\title{
HUME SOBRE A MÁXIMA CAUSAL: CONCEPTIBILIDADE E POSSIBILIDADE*
}

\author{
Rafael Bittencourt Santos** \\ http://orcid.org/0000-0002-2210-6258 \\ rafaelbittencourt@protonmail.com
}

RESUMO Uma das criticas mais contundentes ao argumento de Hume contrário ao status a priori ou logicamente verdadeiro da máxima causal-a de que todo evento deve ter uma causa - é a de Anscombe. Ela critica a passagem de Hume da contingência das associações causais particulares - que este evento deva ter esta causa-para a contingência de qualquer causa-que este evento tenha que ter alguma causa. Meu objetivo é defendê-lo da sua crítica, argumentando que o raciocínio de Hume depende de premissas anteriores do "Tratado da Natureza Humana", particularmente da sua filosofia da percepção e da sua filosofia do tempo. A apreciação dessas premissas torna o seu argumento mais interessante e menos vulnerável às considerações de Anscombe.

Palavras-chave Hume; causalidade; conceptibilidade; possibilidade; percepção.

ABSTRACT One of the most incisive criticisms of Hume's argument against the causal maxim - that every event must have a cause - a priori or logically true status comes from Anscombe. She criticizes Hume's inference from the contingency of particular causal associations - that this event must have this cause - to the contingency of any cause - that this event must have any cause. My aim is to defend him from her criticism, arguing that Hume's

* Artigo submetido em 09/07/2018 e aprovado em 16/01/2019. O presente trabalho foi realizado com apoio do CNPq (Conselho Nacional de Desenvolvimento Científico e Tecnológico - Brasil).

** Universidade Federal do Rio Grande do Sul. Porto Alegre, RS, Brasil.

KRITERION, Belo Horizonte, nº 144, Dez./2019, p. 689-709 
reasoning depends on earlier premises of the "Treatise of Human Nature", particularly its philosophy of perception and philosophy of time. An appreciation of these premises makes his arguments more interesting and less vulnerable to Anscombe's considerations.

Keywords Hume; causality; conceivability; possibility; perception.

\section{Introdução}

Hume defende que a máxima filosófica de que "tudo que começa a existir deve ter uma causa para sua existência" (doravante "máxima causal") não é, para usar termos contemporâneos, logicamente verdadeira ${ }^{1}$ (TNH 1.3.3.1²). G. E. M. Anscombe, por sua vez, em seu artigo "Whatever has a beginning of existence must have a cause': Hume's argument exposed", afirma que o seu argumento não é capaz de estabelecer o que ele pretende provar (1974, p. 151). Hume teria dado um passo em falso no seu raciocínio, passando da contingência de relações causais particulares para a contingência de qualquer causa (isso deve ficar mais claro no decorrer deste artigo) (1974, pp. 149-50), ou teria usado de uma noção tão vaga de conceptibilidade que seria insuficiente para garantir o antigo princípio de Parmênides de que o que é pensável é possível (1974, p. 151). Esta última crítica, aliás, também é levantada por Barry Stroud (1977, p. 50) ao tratar do mesmo tema (o argumento de Hume contra a atribuição do caráter de verdade lógica à máxima causal).

Embora Hume devote pouco à análise da máxima, a sua crítica cumpre um papel importante para o seu sistema. A tese central da Parte 3 do Livro 1 do "Tratado da Natureza Humana", a de que a necessidade atribuída às relações de causa e efeito não é estabelecida ou descoberta pela razão, é enfraquecida, se não simplesmente infundada, se o seu tratamento da máxima causal é

1 Essa formulação é uma aproximação. Compreenda-se logicamente verdadeiro como aquilo cuja negação é contraditória. A noção contemporânea de lógica (e, consequentemente, de verdade lógica) é bastante distinta da usada por Hume, que não é meramente formal e centra-se no conteúdo daquilo que é analisado (sobre isso, é interessante ver Owen, 1999). Alguém poderia propor que "analiticamente verdadeira" captaria melhor o sentido, porém isso não contempla todas as relações visadas por Hume (como as relações entre cores). Outra proposta seria "necessariamente verdadeira", contudo é possível, embora não seja consensual, que ele considere que certas verdades empíricas sejam necessárias. Poder-se-ia propor "que ela não é uma verdade a priori”, o que é uma boa formulação, pois deixa clara a necessidade da experiência para o seu estabelecimento. Porém, podemos considerar como a priori também aquilo cuja falsidade não é contraditória (pelo menos depois da "Crítica da Razão Pura", de Kant), de modo que mesmo essa caracterização não se ajusta bem ao caso. Na seção 1, explico mais precisamente a sua tese.

2 "Tratado da Natureza Humana", livro 1, parte 3, seção 3, parágrafo 1. 
incorreto. Isso afeta diretamente a sua crítica ao argumento cosmológico, o qual se ampara na máxima para demonstrar a existência de Deus, e indiretamente a sua investigação sobre as associações causais particulares (este $x$ que é causado por este $y$ ) porque, embora a máxima não implique, prima facie, que as mesmas causas tenham os mesmos efeitos, já não é mais necessário o apelo à experiência, mas apenas o exame da razão, para determinar a necessidade de uma causa para qualquer evento. Se for admitido, como é comum na história da filosofia, que a relação causal é também uma relação necessária, ${ }^{3}$ então a incisiva crítica humiana da causalidade sequer sobrevive ao primeiro quinto da Parte 3 do Livro 1 do "Tratado".

A crítica de Anscombe não me parece definitiva, ou, ao menos, mais pode ser dito em defesa de Hume. Meu objetivo neste artigo é desenvolver os pressupostos envolvidos no seu argumento, de modo a explorar mais profundamente o "Tratado". Aspectos importantes da sua filosofia da percepção (a sua natureza discreta, tanto fenomenológica quanto temporalmente), a qual não é objeto de análise no artigo de Anscombe, podem enriquecer a pretensa prova de Hume, até mesmo, se eu estiver correto, tornar o seu argumento cogente. Esse é o máximo que pretendo aqui, não sendo minha meta, portanto, a avaliação do mérito das suas premissas.

Gregg Osborne (2005) apresenta uma defesa do tratamento de Hume da máxima causal com a mesma inspiração que a minha, a saber, a partir do exame dos seus pressupostos filosóficos, contudo ela é substancialmente diferente no que concerne à função da teoria das ideias gerais no argumento e à natureza da percepção. Não examinarei o seu artigo detalhadamente, apenas o exporei no que me parece a sua falha principal: ele faz um uso indevido do recurso às ideias gerais, que é incapaz de responder à acusação de falácia feita por Anscombe.

\section{A leitura de Anscombe}

Antes de desenvolver o argumento de Hume, cabe atentar para os termos originais dos quais ele se utiliza. $\mathrm{O}$ seu propósito é mostrar que a máxima causal não é intuitiva nem demonstrável (TNH 1.3.3.3). Nesse contexto, o que se deve entender por intuitivamente certo é o que pode ser extraído imediatamente do conteúdo de uma ideia, em termos atuais, de um conceito. ${ }^{4}$

3 Anscombe analisa essa posição em "Causality and determination" (1993). Não tratarei desse texto aqui porque escapa ao foco deste artigo (a máxima causal).

4 Cabe notar que "conceito" não capta totalmente o sentido de "ideia" (na Modernidade e, especificamente, em Hume) porque uma ideia pode corresponder a uma única coisa, o que é discutível de um conceito (pode-se dizer que é acidental que, sob determinado conceito, exista apenas um objeto). De todo modo, é melhor 
O que é demonstrativamente certo (ou verdadeiro) é o que requer uma cadeia de associações, noutras palavras, uma prova. Um axioma geométrico, por exemplo, pode ser dito intuitivamente certo, porque a percepção da sua verdade depende apenas (ou assim se espera) do exame direto do seu conteúdo. Um teorema, por sua vez, por requerer uma prova, é demonstrável. ${ }^{5}$

O roteiro da seção sobre a máxima causal é este: primeiro, Hume alega que a máxima não tem relação alguma com as relações entre ideias que considera as únicas capazes de provar intuitiva ou demonstrativamente uma proposição, a saber, "a semelhança, as proporções de quantidade e de número, os graus de uma qualidade e contrariedade" (TNH 1.3.3.2 - grifos do texto); segundo, ele desenvolve uma suposta prova de que a máxima não é intuitiva nem demonstrável, a saber, pretendendo mostrar que é possível conceber algo começando a existir sem conceber uma causa para sua existência (TNH 1.3.3.3); terceiro, ele examina quatro argumentos que demonstrariam a necessidade (lógica) de uma causa para qualquer começo de existência (TNH 1.3.3.4-8). Resumirei a minha abordagem ao segundo tópico, porque o primeiro demanda uma explicação da redução de todas as relações intuitivas ou demonstrativas entre ideias àquelas citadas por Hume, para o que sequer ele oferece prova $\mathrm{e}$ que nos afastaria em muito da crítica de Anscombe, e porque o terceiro é um desenvolvimento negativo - a refutação das ditas provas da necessidade lógica da máxima - o que está aquém do objetivo principal da seção: provar que a falsidade da máxima é possível.

Cabe esclarecer a razão do zelo em identificar o tipo de necessidade negada por Hume à máxima causal como lógica. Hume não nega a necessidade da máxima (explícita na expressão "deve"), pelo contrário, a assume. O objetivo da sua investigação subsequente é examinar como derivamos, a partir da experiência, a opinião de que uma causa é necessária para todo evento, uma vez que ela não surge, se ele está correto, da razão (TNH 1.3.3.9). Ou seja, a rusga de Hume sobre o status da máxima causal não é quanto à sua verdade, e sim quanto à sua prova. ${ }^{6}$ Por que Hume não desafia a sua verdade é um tema

aproximar-se a partir do que compreendemos por "conceito" do que, como se faz às vezes, por "representação mental", que leva a distorções a respeito da natureza das ideias, como quando se as resume a "coisas na cabeça". Não me estenderei a respeito desse tópico por não ser o foco deste artigo.

5 O exemplo pode ser infeliz dentro do comentário a Hume em virtude da dificuldade de compreender exatamente a sua abordagem da geometria (em TNH 1.2.4), que pode abrir espaço para não a considerar uma ciência exata. Em contrapartida, a geometria certamente não é experimental como a filosofia natural: não há nela raciocínios de causa e efeito. Escolhi esse exemplo porque em geral a geometria exemplifica uma ciência axiomática e peço ao leitor que desconsidere, aqui, as complicações do tratamento particular que Hume lhe dá.

6 Essa não é uma posição de consenso nos comentários a Hume. Alguns defendem que ele dá um tratamento tão somente regularista ou projetivista da causalidade, de modo que a necessidade é, na verdade, mera 
à parte, interessante e que leva a um exame da natureza da sua filosofia, mas que foge ao meu escopo neste artigo.

Vencidas essas preliminares, olhemos para o seu argumento. Primeiro, Hume passa da formulação inicial da máxima para sua contrapositiva.

Nunca poderíamos demonstrar a necessidade de uma causa para toda nova existência ou para toda nova modificação de existência sem mostrar, ao mesmo tempo, a impossibilidade de que alguma coisa comece a existir sem algum princípio produtivo. E se esta última proposição não puder ser provada, deve-se perder qualquer esperança de jamais provar a primeira. (TNH 1.3.3.3)

\section{Então, passa ao argumento propriamente dito.}

Ora, que a última proposição é inteiramente incapaz de receber uma prova demonstrativa é algo de que podemos nos convencer considerando que, como todas as ideias distintas são separáveis entre si, e como as ideias de causa e de efeito são evidentemente distintas, é fácil conceber que um objeto seja não-existente neste momento e existente no momento seguinte, sem juntar a ele a ideia distinta de uma causa ou princípio produtivo. Portanto, a separação da ideia de uma causa da ideia de um começo de existência é claramente possível para a imaginação. Uma vez, portanto, que não implica contradição ou absurdo, a separação real desses objetos é possível, e por isso não pode ser refutada por nenhum raciocínio baseado nas meras ideias. E, sem isso, é impossível demonstrar a necessidade de uma causa. (TNH 1.3.3.3)

\section{Anscombe assim o reconstrói:}

(1) Todas as ideias distintas são separáveis.

(2) As ideias de causa e efeito são distintas.

(3) $\therefore$ É fácil pensar em um objeto vindo à existência sem pensar em uma causa. $\left(1974\right.$, p. 148) ${ }^{7}$

Anscombe compreende (1) da seguinte maneira: "separável' presumivelmente significa 'tal que alguém pode pensar em um sem eo ipso pensar no outro"' (1974, p. 148), ${ }^{8}$ o que é suficiente para a abordagem nesse momento. Ela também compreende adequadamente (2) ao afirmar que Hume

constância ou uma projeção do espírito sobre a natureza. Pode-se, em uma disputa exegética mais ampla, considerar que Hume toma a máxima como uma espécie de orientação prática, sem se comprometer com a sua verdade. Não tratarei dessas polêmicas aqui. Seja qual for a nossa posição acerca do status da máxima causal para Hume, ela não pode ser baseada em uma concepção rasa e pouco convincente do que é conceber, que é um dos pontos da crítica de Anscombe a Hume.

7 As traduções do texto de Anscombe são minhas. No original: "(1) All distinct ideas are separable (2) The ideas of cause and effect are distinct. (3) $\therefore$ It will be easy to think of an object's coming into existence without thinking of a cause."

8 No original: "“'separable' presumably means 'such that one can think of one without eo ipso thinking of the other"'. 
está dizendo que "as ideias de quaisquer objetos que sejam causas e efeitos são distintas umas das outras" (1974, p. 148), ${ }^{9}$ isto é, não é que efeitos não pressuponham (e, logo, não estejam intrinsecamente relacionados a) causas e vice-versa, pois é óbvio que não existem causas sem efeitos nem efeitos sem causas, e sim que aquilo que identificamos como causa é distinto daquilo que identificamos como efeito. Hume trata disso de modo bastante claro:

Todo efeito pressupõe necessariamente uma causa, já que efeito é um termo relativo, cujo correlato é causa. Mas isso não prova que todo ser tenha de ser precedido por uma causa, assim como, do fato de que todo marido deve ter uma esposa não se segue que, por isso, todo homem tenha de ser casado. (TNH 1.3.3.8)

A análise de Anscombe segue: "(4) $\therefore$ A separação da ideia de uma causa daquela de um começo de existência é possível para a imaginação." ${ }^{10}$ Aqui, ela oferece duas compreensões possíveis dessa proposição: “[1] que é possível imaginar um começo de existência sem imaginar uma causa, e [2] que é possível imaginar um começo de existência sem uma causa" (1974, p. 148). ${ }^{11}$ Anscombe não detalha a diferença precisa que vê entre ambas, mas toma a segunda como a almejada por Hume em virtude de a primeira ser demasiadamente próxima de (3).

O que ela está mirando deve ficar mais claro nos passos seguintes da sua análise. "(5) $\therefore$ A separação atual destes objetos é de tal modo possível que ela não implica contradição ou absurdo." (1974, p. 149). ${ }^{12}$ E continua: "Isso leva à pergunta 'Que objetos?'A resposta, enquanto concerne a um deles, é manifesta: "um começo de existência"” (1974, p. 149). ${ }^{13}$ E qual seria o outro objeto? "A única resposta que temos é "uma causa"” (1974, p. 149). ${ }^{14}$

A partir daí, o argumento de Hume poderia seguir por dois caminhos. Primeiro, podemos compreendê-lo a partir de casos particulares. Podemos imaginar, por exemplo, um coelho começando a existir e as possíveis causas para isso. Isso, segundo ela, estaria de acordo com a doutrina de Hume sobre as ideias abstratas (1974, p. 149), a de que tudo que podemos conceber é

9 No original: "the ideas of whatever objects are causes and effects are distinct from one another".

10 No original: "(4) $\therefore$ The separation of the idea of a cause from that of a beginning of existence is possible for the imagination."

11 No original: "[1] that it is possible to imagine a beginning of existence without imagining a cause, and [2] that it is possible to imagine a beginning of existence without a cause".

12 No original: (5) $\therefore$ The actual separation of these objects is so far possible, that it implies no contradiction or absurdity."

13 No original: "This makes one ask 'What objects?' The answer, as far as concerns one of them, is plain: it is 'a beginning of existence'".

14 No original: "The only answer we have is 'a cause'". 
particular e determinado. É possível imaginar um coelho vindo à existência sem seus pais coelhos, por exemplo, e assim por diante. Contudo, Anscombe nota, isso não garante a conclusão desejada, a de que algo possa vir a existir sem causa alguma. Isso implicaria "(6) Para qualquer começo (ou modificação) de existência $\mathrm{E}$ e qualquer causa particular $\mathrm{C}$, eu posso imaginar a ocorrência de E sem C", ${ }^{15}$ o que implica “(7) Para qualquer começo (ou modificação) de existência $\mathrm{E}$, e qualquer causa particular $\mathrm{C}$, pode ser esperado [supposed] que E aconteça sem C: i. e. não há contradição ou absurdo na suposição..", ${ }^{16}$ mas não implica "(8) eu posso imaginar isto: existe um começo (ou modificação) de existência sem qualquer causa" (1974, p. 149). ${ }^{17}$ Ou seja, da possibilidade de imaginar quaisquer pares de objetos, um sendo o que começa a existir e outro sendo a sua causa, sem relacioná-los causalmente, não se segue a possibilidade de imaginar um objeto vindo a existir sem causa alguma.

Anscombe exprime a falácia de modo direto, de "Para qualquer, é possível que não..." não implica "É possível que para nenhum..." (1974, p. 150), ${ }^{18}$ e a exemplifica: de "Para qualquer cor, posso imaginar que uma rosa não é dessa cor" não se segue que "posso imaginar que uma rosa não tenha nenhuma cor." (1974, p. 150). ${ }^{19} \mathrm{O}$ exemplo é um tanto infeliz, pois alguém poderia afirmar a possibilidade, estranha, mas não absurda, de uma rosa incolor. De todo modo, excluindo essa opção, o seu raciocínio é claro. Temos um conjunto com todas as cores, as quais podem ser atribuídas a uma rosa. Ao pensar em cada cor em particular, podemos imaginar uma rosa que não seja dessa cor. Isso não implica que podemos pensá-la sem qualquer cor do conjunto, porque nosso teste estabelece a contingência de cada relação particular, o que é insuficiente para desqualificar a necessidade de alguma relação, desconsiderando os pares específicos. $^{20}$

15 No original: 6) For any beginning (or modification) of existence $E$ and any particular cause $C$, I can imagine E's happening without C".

16 No original: "(7) For any beginning (or modification) of existence $E$, and any particular cause $C$, E can be supposed to happen without C: i. e. there is no contradiction or absurdity in the supposition."

17 No original: "(8) I can imagine this: there is a beginning (or modification) of existence without any cause".

18 No original: "For any, it is possible that not..." não implica "It is possible that for none...".

19 No original: "From: 'For any colour, I can imagine that a rose is not that colour' does not follow: 'I can imagine that a rose has no colour"'.

20 Poder-se-ia perguntar sobre a razoabilidade de se comparar a relação entre causa e efeito com a relação entre acidente e substância (ou como se queira chamar a relação da cor com o objeto colorido). O que está em jogo aqui não é a semelhança da relação causal com qualquer outra, mas a admissibilidade de um tipo de argumento ou raciocínio. Em verdade, a relação substância/acidente propicia um exemplo mais clássico: admite-se (nas teorias que fazem tal distinção) que uma substância pode existir sem tal e tal acidente, mas a acidentalidade não é contingente (isto é, uma substância não pode existir sem qualquer acidente). 
Falhando esta via, podemos compreender o argumento de outro modo, não particularizando os objetos. Isso, segundo Anscombe, seria abandonar a posição de Hume quanto às ideias abstratas (1974, p. 150). O argumento ficaria assim:

Podemos imaginar algo vindo à existência sem uma causa.

$\therefore$ É possível (i.e. não há contradição em supor) que algo venha a existência sem uma causa. $(1974, \text { p. } 150)^{21}$

Nesse caso, contudo, o argumento soa superficial e um tanto obscuro. O que é imaginar algo vindo a existir sem uma causa?

Pois se eu digo que posso imaginar um coelho vindo a existir sem um pai coelho, que assim seja [well and good]: imagino um coelho vindo a existir, e nossa observação de que não há um coelho pai. Mas o que estou a imaginar se imagino um coelho vindo a existir sem uma causa? Bem, eu apenas imagino um coelho vindo a existir. Que isto seja a imaginação de um coelho vindo a existir sem uma causa não é nada senão, como fora, o título do retrato [picture]. De fato, posso formar uma imagem e dar meu retrato e título. Mas da minha capacidade de fazer isso, nada se segue a respeito do que é possível supor 'sem contradição ou absurdo' como vigorando na realidade. (1974, pp. 150 - grifos do texto) $)^{22}$

Stroud argumenta de modo semelhante.

Se o teste sobre se uma certa coisa é concebível ou não envolve somente uma tentativa cuidadosa de efetuar um certo ato mental e um juízo sincero do seu grau de sucesso, então a conceptibilidade de alguma coisa começando a existir sem uma causa não estabelece a possibilidade de alguma coisa começar a existir sem uma causa. (1977, p. 50 - tradução minha) ${ }^{23}$

\section{Ele recorre a um exemplo que atribui a William Kneale (1949).}

A Conjectura de Goldbach, de que todo número par é a soma de dois primos, nunca foi provada ou refutada. Uma grande quantidade de números pares foram testados e cada um foi verificado como sendo a soma de dois primos, mas nenhuma demonstração

21 No original: "We can imagine something's coming into existence without a cause. $\therefore$ It is possible (i.e. there is no contradiction in supposing) that something comes into existence without a cause."

22 No original: "For if I say I can imagine a rabbit coming into being without a parent rabbit, well and good: I imagine a rabbit coming into being, and our observing that there is no parent rabbit about. But what am I to imagine a rabbit coming into being without a cause? Well, I just imagine a rabbit coming into being. That this is the imagination of a rabbit coming into being without a cause is nothing but, as it were, the title of the picture. Indeed I can form an image and give my picture and title. But from my being able to do that, nothing whatever follows about what is possible to suppose 'without contradiction or absurdity' as holding in reality."

23 No original: "If the test of whether or not a certain thing is conceivable involves only a conscientious attempt to perform a certain mental act and a sincere judgment of the degree of one's success, then the conceivability of something's beginning to exist without a cause does not establish the possibility of something's beginning to exist without a cause." 
de um lado ou de outro jamais foi fornecida. Parece fácil conceber a Conjectura de Goldbach sendo provada algum dia, mas isso não é dizer que é fácil crer que ela será provada. Mas eu também posso concebê-la sendo refutada, alguém provando a sua negação, talvez encontrando um número par muito grande que não é a soma de dois primos. Eu posso conceber um computador apresentando um amanhã. (Stroud, 1977, p. 50 - tradução minha) $)^{24}$

Enquanto Anscombe lança dúvidas sobre o conteúdo do ato imaginativo que ilustra, Stroud pressiona do outro lado: caso o seu conteúdo seja tal como o consideramos. Se a crítica de Anscombe está correta, a conexão entre o concebível e o possível é enfraquecida. A de Stroud, por sua vez, é ainda mais incisiva, porque apela para um caso em que é de comum acordo que se trata de uma verdade ou falsidade necessária. A possibilidade de imaginar a Conjectura de Goldach refutada, se ela for verdadeira, é a possibilidade de imaginar uma contradição, algo necessariamente falso, e o mesmo ocorre no caso de ela ser falsa e ser possível imaginá-la sendo demonstrada. Desata-se a relação entre ser imaginável ou concebível e ser possível tal como Hume a estabelece, se esse é um caso exemplar da sua aplicação.

Quando entramos nesse nível de generalidade quanto à imaginação ou quanto ao que é imaginar algo, os exemplos ficam obscuros e é difícil dizer o que é, de fato, o conteúdo de um ato imaginativo. Se o argumento de Hume segue essa via, ele é de fato obscuro e pouco esclarecedor. Todavia, o critério de conceptibilidade tem uma função tão importante na sua filosofia que é legítimo, neste caso, apelar para o princípio de caridade.

\section{A defesa de Osborne}

Osborne alega que, dadas duas ideias distintas, $\mathrm{E}_{1}$ e $\mathrm{E}_{2}$, a suposta causa e o suposto efeito, respectivamente, para admitirmos que a ideia de $\mathrm{E}_{2}$ é distinta da ideia geral de uma causa (ou da ideia de qualquer causa), basta considerarmos o modo como as ideias abstratas funcionam:

A ideia geral ou abstrata de uma causa, nesse tratamento, é apenas a ideia de um evento particular (de um $\mathrm{E}_{1}$, por exemplo) que alcança um sentido geral ao ser anexado ao

24 No original: "Goldbach's Conjecture to the effect that every number is the sum of two primes has never been proved or disproved. A great many even numbers have been tested and each has been found to be the sum of two primes, but no general proof one way or the other has ever been found. It seems easy to conceive of Goldbach's Conjecture's being proved one day, although that is not to say that it is easy to believe that it will be proved. But I can also conceive of its being disproved, of someone's proving its negation, perhaps by finding a very large even number that is not the sum of two primes. I can conceive of a computer's coming up with one tomorrow." 
termo "causa", um termo que retoma a disposição de evocar as outras ideias anexadas a ele, ideias que são elas mesmas ideias de eventos particulares. O conjunto de tais ideias é denominado por Don Garrett "conjunto de evocação" [revival set $]$ [1997, p. 24]. Para determinar se a ideia de um $\mathrm{E}_{2}$ é distinta ou não da ideia abstrata ou geral de uma causa, portanto, o que precisamos determinar é se há ou não há algum membro do conjunto de evocação do termo "causa" do qual ela não é distinta. Dizer que a ideia de E não é distinta da ideia abstrata ou geral de uma causa seria, portanto, dizer que há, pelo menos, um membro do conjunto de evocação do qual ela não é distinta. (2005, p. 229 - grifo meu - tradução minha $)^{25}$

Para avaliar a separabilidade de $\mathrm{E}_{2}$ de qualquer causa, precisaríamos avaliar a separabilidade de $\mathrm{E}_{2}$ dos membros do conjunto de causas. Aqui, Osborne é suscetível à crítica de Anscombe à inferência de "para qualquer, é possível que não..." para "é possível que para nenhum ...". Mostrar que não há membro do conjunto de evocação do termo "causa" que não possa ser distinto de $\mathrm{E}_{2}$ é insuficiente para mostrar que $\mathrm{E}_{2}$ é independente do conjunto. A contingência da relação de $\mathrm{E}_{2}$ com cada causa possível não acarreta a sua independência de qualquer causa.

\section{A natureza da percepção}

\subsection{Do imaginável ao possível}

Hume compreende a percepção como discreta em sua natureza, isto é, como constituída de elementos simples e distintos. Essa é uma visão bastante contestada na Filosofia Contemporânea, mas não é do meu interesse aqui contrastá-la com as abordagens atuais, apenas conectá-la com o seu tratamento da causalidade. Isso significa não só que a nossa experiência pode ser depurada até seus constituintes mais básicos, mas também que tudo o que podemos pensar e imaginar deve poder ser reduzido àquilo que experienciamos nesse nível mais elementar, se o empirismo a que adere é correto. A existência de um conceito que não pode ser reduzido aos elementos básicos da experiência seria uma refutação da sua posição. Como não é o mérito do seu empirismo que aqui está sendo avaliado (diretamente), não me deterei nesse ponto.

25 No original: "The abstract or general idea of a cause, on that account, is just the idea of a particular event (that of $\mathrm{E}_{1}$, for example) which achieves general signification by being annexed to the term "cause," a term that revives the disposition to call up other ideas annexed to it, ideas which are themselves ideas of particular events. The set of such ideas is referred to by Don Garrett as the term's "revival set." To determine whether or not the idea of $E_{2}$ is distinct from the abstract or general idea of a cause, therefore, what we have to determine is whether or not there is any member of the term "cause"'s revival set from which it is not distinct. To say that the idea of $E_{2}$ is not distinct from the abstract or general idea of a cause would thus be to say that there is at least one member of that revival set from which it is not distinct." 
Aquilo que sentimos, isto é, que percebemos via nossos sentidos, Hume chama "impressões" (TNH 1.1.1.1), e as impressões básicas - aquelas que não podem ser reduzidas a nenhuma outra - "impressões simples", enquanto as que são compostas por outras impressões, "complexas" (TNH 1.1.1.2). Tome uma maçã: ela tem uma determinada cor, um determinado sabor e assim por diante. A maçã como um todo, ou a percepção da maçã como um todo, é uma impressão complexa, e cada um dos seus elementos é uma impressão simples.

Hume chama "ideias", por sua vez, aquilo que constitui o conteúdo do nosso pensamento (TNH 1.1.1.1). A elas, também se aplica a divisão entre simples e complexas. Sendo elas o conteúdo do pensamento e sendo tudo o que podemos conceber derivado da experiência, elas devem ser derivadas das impressões. Isso não significa que só podemos pensar exatamente aquilo que experienciamos tal como o experienciamos: os elementos das nossas experiências podem ser rearranjados. Eu posso pensar em algo cuja metade inferior se assemelha ao corpo de um cavalo e cuja metade superior se assemelha ao corpo de um homem (um centauro). Embora eu nunca tenha visto um todo assim, das partes, já tive experiência.

O importante, portanto, é que as ideias complexas possam ser analisadas em ideias simples e estas, por sua vez, devem corresponder a impressões simples já experienciadas (TNH 1.1.1.7) (o que ficou conhecido como "Princípio da Cópia"). Essa última relação, central à filosofia humiana, não é exatamente provada, mas assumida por Hume, o que ele reconhece. ${ }^{26}$ Seja como for, ela é central porque assegura a conexão entre o pensamento e a realidade, isto é, ela garante que o pensável não pode ir além do possível. É claro que podemos pensar o que vai de encontro às leis naturais, porém elas não são, ao menos no "senso comum filosófico", os limites do possível. A realidade poderia ser tal que outras leis determinassem os eventos. De todo modo, a relação direta entre ideias e impressões simples não é importante apenas para a intriga com o racionalismo (que defende a existência de ideias que não podem ser resumidas à experiência), mas para a própria confiança de que os sentidos nos revelam o real, uma vez que Hume não pode apelar para nenhum critério de correção externo

26 "É impossível provar, por uma enumeração exaustiva de todos os casos, que isso se dá com todas as nossas impressões e ideias simples. Qualquer pessoa pode se convencer disso, examinando tantas quantas queira. Mas se alguém negar essa semelhança universal, o único meio que vejo de o convencer é pedir-lhe que mostre uma impressão simples que não tenha uma ideia correspondente, ou uma ideia simples que não tenha uma impressão correspondente" (TNH 1.1.1.5). Don Garrett, por seu turno, argumenta que esse princípio é uma generalização empírica genuína (ver Garrett, 1997, pp. 43-49). De fato, é parte do projeto do "Tratado" mostrar que é possível dar conta do conhecimento humano com base na experiência, todavia a adesão a esse princípio no seu início deve ser vista como uma espécie de aposta a ser corroborada. Acerca do assunto deste artigo, essa é uma divergência menor, de modo que não a explorarei. 
à experiência para assegurá-la como fonte apropriada para o conhecimento (como Descartes faz, ao apelar para a bondade divina - Meditação Quarta, AT 7, p. 62; Meditação Sexta, AT 7, p. 9077). Se é possível alguma ideia simples que não seja cópia de uma impressão simples, ou o (seu) empirismo é falso, ou perde-se o lastro do pensamento na experiência.

Isso não significa que a realidade não possa extrapolar a nossa experiência. Pode haver coisas das quais não podemos no momento ter uma ideia adequada, porque não tivemos a experiência apropriada (como o sabor de uma fruta que nunca provamos -TNH 1.1.1.9); ou que estão para além da nossa experiência possível, porque demandam sentidos que não temos (como a visualização das cores para um cego - TNH 1.1.1.9 - ou de um ser que tenha um sentido outro que os nossos - IEH 2. ${ }^{28}$ ); ou que estão para além de qualquer experiência possível, porque são empiricamente inacessíveis ${ }^{29}$ (como as qualidades originais da alma - TNH Intro.8). A experiência não resume a realidade.

O que não pode ser o caso é que os conteúdos da experiência não sejam originados da realidade, isto é, que as impressões simples sejam meras invenções do espírito. ${ }^{30}$ Noutras palavras, não pode ser o caso que elas não tenham origem no que existe, como se um Gênio Maligno (para ilustrar com o instrumental cartesiano) criasse ou modificasse toda a nossa experiência. Ainda que o arranjo dos elementos simples possa ser inventado ou iludido, os elementos simples não podem.

Poder-se-ia argumentar que a eliminação das amarras do pensamento na experiência não é algo dramático: basta que se identifique se esta ideia simples tem ou não uma impressão simples que lhe corresponde, e assim se verifica se ela tem base empírica ou não. Contudo, como uma impressão é a própria experiência de algo, não é possível, seguindo Hume, o acesso a uma impressão passada. Impressões são sempre presentes. Recordar, para Hume, é pensar. Desse modo, nenhuma inspeção das nossas ideias garantiria que elas têm conexão com algo experienciado. Também aquilo que nós pensamos contraditório passa a ser possível, uma vez que não podemos nos assegurar que os conteúdos das ideias que tomamos como contraditórias correspondam a algo real.

27 Referência ao volume e às páginas da edição Adam-Tanerry das obras de Descartes.

28 "Investigação sobre o Entendimento Humano", seção 2, parágrafo 7.

29 Esse é um caso controverso na exegese de Hume, pois muitos intérpretes diriam que a sua filosofia exclui da existência o que não pode afetar a experiência. Como a divergência sobre o Princípio da Cópia, ela importa menos para o tópico central deste artigo.

30 Quanto ao caso do tom ausente de azul (TNH 1.1.1.10), que, à primeira vista, parece refutar o Princípio da Cópia, Garrett (1997, pp. 50-52) oferece uma boa explicação sobre a sua adequação ao princípio. 
Ao atar as ideias às impressões, isto é, o pensamento à experiência, Hume garante a transição do pensável ao possível. Ao rearranjar as ideias simples ao seu bel-prazer, a mente pode ir além do factual ou do efetivamente real. Ela pode, por exemplo, pensar um evento sem uma causa, mesmo que (alegadamente) todo evento precise de uma causa. O que garante que as configurações que ela estabelece são possíveis é o seu fundamento na experiência ou na realidade.

Fica evidente a importância da possibilidade de redução de todas as ideias complexas às ideias simples, da correspondência das ideias simples às impressões simples e da autenticidade das impressões simples (da impossibilidade de elas serem inventadas ou, pelo menos, da irrazoabilidade dessa suposição). Ocorre que isso pode ser insuficiente para dar conta da nossa compreensão do mundo e da nossa linguagem. $\mathrm{O}$ arranjo livre de ideias simples pode dar conta da nossa referência a particulares que não existem, como centauros e lobisomens, mas pode ser insuficiente para dar conta do nosso uso de termos gerais. Aqui, o percurso recém-feito de conexão do pensável ao experienciável pode se revelar muito restritivo: nós observamos seres humanos, não observamos a humanidade. Diante disso, o ato de pensar as espécies, por assim dizer, pode se tornar um fenômeno sem explicação.

É nesse contexto que se dá a discussão a respeito da natureza das ideias abstratas. Para dar conta do nosso uso de termos gerais, poder-se-ia fazer como Locke, que postula a existência de ideias sem algumas determinações ("Ensaio" 3.3.6- $\left.8^{31}\right)$. A concepção de um ser humano, por exemplo, exigiria a abstração daquilo que não é comum a todos os seres humanos e a retenção apenas do que lhes é comum. Desse modo, a ideia de ser humano não poderia ter em si a ideia de um peso particular, de uma altura particular e assim por diante ("Ensaio" 3.6.9).

A abordagem de Hume é dupla. Primeiro, ele pretende mostrar a impossibilidade das ideias abstratas tais como as propostas por Locke (TNH 1.1.7.3-6). Segundo, ele pretende mostrar que se pode dar conta do uso dos termos gerais de modo alternativo (TNH 1.1.7.7-18). Perceba-se a importância dos dois movimentos: se a solução de Locke é inadequada, a sua crítica não pode acarretar o abandono da experiência ou sensibilidade como origem do conhecimento. 32

31 "Ensaio sobre o entendimento humano", livro 3, capítulo 3, seções 6 a 8.

32 Não se pretende aqui um veredito a respeito da teoria de Locke, uma vez que pode haver uma resolução desse tensionamento a partir do seu próprio desenvolvimento, mas um esclarecimento da abordagem de Hume. Além disso, há diferenças relevantes entre os dois filósofos na compreensão dos termos centrais à discussão. Uma comparação cuidadosa precisaria fazer justiça a essas assimetrias. 
Hume apresenta três argumentos para mostrar a impossibilidade das ideias sem determinações. Nos três podemos perceber a preocupação com a manutenção da relação entre o pensamento e a realidade. O primeiro (TNH 1.1.7.3) concerne à impossibilidade de distinguir o que não é distinto. Isso soa como um jogo de palavras. Contudo, expressa a dificuldade da pretensão de separar de uma ideia o que lhe seria constituinte. Admitindo-se que o nosso arcabouço original de ideias é composto apenas por ideias simples e sendo uma ideia complexa uma composição de ideias simples, a formação de uma ideia abstrata resultaria apenas da exclusão de ideias simples da sua composição. Para tanto, seria necessário conceber João sem estatura, por exemplo, para se ter uma ideia de ser humano. Não teríamos um ser humano nem João, porque ter uma estatura é algo que pertence a ambos.

$\mathrm{O}$ segundo (TNH 1.1.7.4-5) concerne à relação de cópia entre impressões e ideias, de modo que ideias não poderiam ter qualidades distintas das impressões. A possibilidade de conceber uma ideia incompleta (um ser humano sem estatura) implicaria a possibilidade de haver uma impressão incompleta. Isso porque a única diferença admitida entre impressões e ideias é a do seu modo de aparecimento à mente: impressões são sentidas, ideias são pensadas (o que corresponde à diferença de força e vividez mencionada por Hume - ver TNH 1.1.1.1). A concepção de uma ideia incompleta acarretaria o abandono do Princípio da Cópia, porque teríamos uma ideia cujo conteúdo não corresponderia a alguma composição possível de impressões simples. O lastro na experiência se manteria em virtude da gênese das ideias abstratas: elas ainda seriam formadas a partir das ideias simples, obtidas pela experiência, sem a adição de nenhuma propriedade. Todavia, o concebível deixaria de ser possível e o impossível passaria a ser concebível (um triângulo que não é isósceles nem escaleno nem equilátero não pode existir, mas precisaria poder ser imaginado de algum modo). ${ }^{33}$

O terceiro concerne à relação entre a ideia e o objeto da ideia. Hume alega que "formar a ideia de um objeto é o mesmo que simplesmente formar uma ideia" (TNH 1.1.7.6). A ideia é o objeto pensado, por assim dizer. Uma ideia que não é ideia de algum objeto é um contrassenso, dessa perspectiva. "Objeto", aqui, deve-se explicitar, tem uma conotação ampla, não se referindo apenas às coisas que vemos e tocamos. Sons, sabores e sentimentos podem ser objetos. Hume pretende inferir a natureza das ideias a partir da natureza dos objetos. onde algumas partes de diversas ideias diferentes e incompatíveis são agrupadas" ("Ensaio" 4.7.9). 
Em terceiro lugar, trata-se de um princípio geralmente aceito na filosofia que tudo na natureza é inteiramente individual, e que é inteiramente absurdo supor a existência real de um triângulo que não possua uma proporção precisa entre seus lados e ângulos. Se, portanto, isso é absurdo de fato e na realidade, deve ser absurdo também no domínio das ideias - pois nada a respeito do qual podemos formar uma ideia clara e distinta é absurdo ou impossível. (TNH 1.1.7.6 - grifos do original)

Em que pese o possível estranhamento diante de uma inferência dos objetos às ideias por parte de Hume, ${ }^{34}$ note-se a insistência de que o realmente impossível deve forçosamente ser inconcebível. $\mathrm{O}$ argumento tem ares metafísicos: a impossibilidade não se refere às limitações das leis naturais, e sim às limitações da própria natureza dos objetos.

Hume recorre às relações de semelhança entre as ideias. Uma ideia particular, quando associada a um termo geral, passa a representar aquilo que ela tem de semelhante com as demais significadas pelo termo. Berkeley, ${ }^{35}$ nesse ponto, é mais claro: ele refere-se de modo explícito ao direcionamento da atenção ao aspecto que importa da ideia.

[...], embora a ideia que tenho em vista ao fazer a demonstração [de uma proposição a respeito dos triângulos] seja, por exemplo, a de um triângulo retângulo isósceles, cujos lados são de determinada extensão, posso, não obstante, estar seguro de que tal demonstração se estende a todos os demais triângulos retilíneos, de qualquer classe ou tamanho que sejam. E isso porque nem o ângulo reto, nem a igualdade, nem a extensão determinada dos lados estão envolvidos na demonstração. É verdade que o diagrama que tenho em vista inclui todos esses particulares, mas nesse caso, na prova da proposição, não se faz a menor menção a eles. (PHK. Introdução. $16^{36}$ )

Um triângulo particular representa a classe dos triângulos em virtude do uso que se faz dele. Analogamente, uma ideia particular representa uma classe de ideias em virtude do uso que se faz dela. É apenas aquilo que é semelhante a todas as ideias do conjunto que é importante no seu uso. Um triângulo retângulo isósceles pode representar os triângulos retângulos isósceles, os triângulos retângulos, os triângulos ou as figuras bidimensionais a depender do uso que se faz dele, o que por sua vez determina o que se deve levar em consideração e determina o critério de semelhança.

34 À primeira vista, parece-me que podemos interpretar o recurso ao princípio de que tudo na natureza é individual de duas maneiras: como a identificação das impressões com os objetos (ainda que como presentes à mente) ou como um apelo a uma posição de senso comum, com autoridade até que se mostre o contrário ou compartilhada pelo seu interlocutor (sendo Locke, isso é admissível - ver "Ensaio" 3.3.11).

35 A abordagem de Hume é inspirada na de Berkeley, o que ele reconhece explicitamente, considerando-a "uma das maiores e mais valiosas [descobertas] feitas recentemente na república das letras" (TNH 1.1.1.1).

36 Referência ao "Tratado sobre os princípios do conhecimento humano", introdução, parágrafo 16. 
Ao recorrer à relação de semelhança, Hume pretende explicar o mecanismo pelo qual a mente conseguiria percorrer as demais ideias do conjunto, ainda que sem esgotá-las (o que seria impossível, porque são potencialmente infinitas) (TNH 1.1.7.7). Esse seria um processo falível e a mente pode falhar em reconhecer uma relação inapropriada, especialmente "no caso de ideias abstrusas e compostas" (TNH 1.1.7.8).

A estratégia de Osborne, já explorada, não é adequada tanto porque é vulnerável à crítica de Anscombe de que a separabilidade dos casos particulares não implica a separabilidade de um evento do conceito de causa. A estratégia é a avaliação do caso geral. A respeito disso, Anscombe equivoca-se ao crer que a abordagem direta do caso geral viole a posição de Hume a respeito das ideias abstratas. Isso porque falar em "uma causa" não implica não ter nenhuma ideia determinada em mente, e sim direcionar a atenção apenas para aquilo que faz, dessa ideia, a ideia de uma causa, assim como o geômetra, quando fala em "um triângulo", direciona a atenção apenas àquilo que é comum aos triângulos em sua figura determinada. O caso relevante é, precisamente, a avaliação do que é ser "uma causa".

Antes de seguir na resposta a Anscombe, podemos avaliar o caso da Conjectura de Goldbach, enfatizado por Stroud. É somente em um sentido inapropriado de conceber que podemos dizer que alguém pode conceber um computador mostrando um número par que não seja a soma de dois primos, porque ali não está justamente o número. É uma espécie de concepção às escuras: o conteúdo (a ideia) que importa falta, não se apresenta. Se eu imagino alguém dizendo "um computador mostrou o número" ou qualquer situação que não mostre o número ou a demonstração, isso não é imaginar a sua falsidade, mas alguém proclamando a sua falsidade ou alguém agindo como se ela fosse falsa. É como se alguém nos mostrasse um quadro em branco e dissesse que é a representação de uma vaca comendo capim. "Onde está o capim?", perguntamos, "A vaca comeu", "E onde está a vaca?", "Foi embora". O conteúdo que afirmamos estar ali não está. Se a Conjectura é verdadeira, é impossível conceber um número que a falseie, de modo que esse nunca poderá ser o conteúdo da minha imaginação. Se ela é falsa, o mesmo ocorre: a demonstração da sua verdade nunca poderá ser o conteúdo da minha imaginação. ${ }^{37}$

37 Berto e Schoonen (2018) têm uma crítica bastante convincente à noção de conceptibilidade (e sua relação com "possibilidade") de Hume à luz da discussão contemporânea sobre representação e retomam o caso da Conjectura de Goldbach (Berto e Schoonen, 2018, p. 2711). Uma defesa definitiva de Hume, ou da filosofia humiana, precisa confrontar a sua análise, que consiste, resumidamente, em mostrar que o critério humiano ou é muito restrito e não dá conta do que consideramos possível (se conceptibilidade for representação 


\subsection{O tempo}

Em outro artigo, "Times, Beginnings, and Causes", Anscombe reconhece que a teoria da causalidade de Hume depende da sua filosofia do espaço e do tempo. Em virtude da sua avaliação da filosofia do espaço e do tempo de Hume, ela considera a sua teoria causal limitada por não dar conta de todos os casos (1986, p. 89). Sua avaliação se dá a partir de um exemplo bastante específico a respeito da conexão entre uma causa particular e um efeito particular e abre uma exceção estrita à teoria. Não sendo esse o tópico, ainda que seja de interesse para uma discussão mais ampla, exporei de modo breve a filosofia do tempo de Hume, uma vez que é peça importante para a sua teoria da causalidade, sem dar conta da análise de Anscombe em "Times, Beginnings, and Causes".

Hume concebe o tempo como composto de partes últimas não temporais (TNH 1.2.2.4), isto é, como a passagem de momentos que não são eles mesmos dotados de duração, porque esta está justamente na passagem. A analogia mais esclarecedora é a do filme: um filme é composto por fotos, cada qual estática, e a sucessão das fotos dá a impressão de movimento. Cada momento no tempo seria como uma foto em um filme. $\mathrm{O}$ argumento para tanto e a polêmica em que ele se insere não cabem aqui.

Sendo o tempo discreto, isto é, constituído por partes distintas, cada qual com sua própria realidade, a percepção também o é, porque percebemos a cada momento, o que significa que a cada momento recebemos uma nova impressão, e que podemos distinguir a impressão de $t_{1}$ da impressão de $t_{2}$ com base no momento em que cada uma foi experienciada. Pode ser o caso que o objeto permaneça ao longo do tempo, mas isso não se estende a sua percepção, que se dá em um determinado instante. É preciso que a cada instante os raios de luz atinjam a retina e, para usar do vocabulário moderno, estimulem os espíritos animais para que exista a impressão de um objeto.

Podemos pensar numa percepção que se estenda ao longo do tempo, isto é, numa percepção que seja composta por dois ou mais momentos. Ela será uma percepção complexa, sendo a temporalidade parte da sua complexidade. Ela deve poder, portanto, ser reduzida a seus elementos mais simples, cada qual despido de duração. ${ }^{38}$

mental ou pictórica) ou muito amplo, tornando possível até mesmo o que consideramos contraditório (se conceptibilidade for representação linguística). Isso, todavia, está para além do escopo deste artigo, porque demanda uma inspeção mais profunda da filosofia de percepção de Hume do que o necessário para a avaliação da objeção de Anscombe ao seu tratamento da máxima causal.

38 Hume trata de modo análogo a extensão: a ideia complexa de extensão seria composta de ideias simples que não seriam extensas nelas mesmas, mas quando combinadas (TNH 1.2.3.3). 


\section{A causalidade}

A relação causal, segundo Hume, dá-se ao longo do tempo. A causa, ele argumenta, deve ser temporalmente anterior ao efeito (TNH 1.3.2.7). Não é necessário examinar o seu raciocínio aqui, isso basta para que precisemos examinar a relação entre o tempo e a percepção na sua filosofia. ${ }^{39}$

A relação causal requer, portanto, ao menos dois momentos. Isso significa que entre um objeto que começa a existir e a sua causa há uma distância temporal ${ }^{40}$ estando ambos em instantes distintos. Noutras palavras, imaginar um objeto que começa a existir sem uma causa para a sua existência é imaginar algo que exista em $t_{2}$ sem que nada tenha ocorrido em $t_{1}$, ou que $t_{1}$ sequer seja necessário. A independência dos momentos no tempo, decorrente da sua natureza discreta, parece ser suficiente para garantir a independência conceitual ou lógica do que ocorre a cada instante, possibilitando a concepção de um começo de existência sem causa, mas pode ser que mais seja preciso ser dito para tornar a posição de Hume robusta.

A pergunta-chave é: a ideia de um objeto pode fazer referência a outro? ${ }^{41}$ A resposta deve ser feita a despeito de qualquer adição que a experiência possa fazer a nossa concepção daquele objeto. Nós podemos ter expectativas, podemos dizer que a fumaça, em algum sentido, faz referência ao fogo, que o controle faz referência à televisão, mas nisso estamos considerando o que adquirimos vivendo e observando. O problema trata do caráter intuitivo ou demonstrável da máxima causal, isto é, da possibilidade de conhecê-la a despeito do que a experiência nos ensina. Uma resposta que indique que nossas ideias apontam para outras em virtude do que aprendemos não vai de encontro à filosofia humiana, pelo contrário.

O exercício de abstração (ou de depuração do que é adquirido da experiência) é longe de ser "fácil" como Hume o afirma, mas é do seu costume apontar como fácil, evidente e óbvio aquilo que não o é. Todavia, não precisamos, para compreender o seu argumento, insistir em fechar os olhos e imaginar como seria julgar sem ter experiência alguma - se teríamos a expectativa de algo ser a causa de uma cortina de fumaça, se essa fosse a nossa primeira experiência

39 Para uma análise detalhada do argumento de Hume para a prioridade temporal das causas em relação aos seus efeitos, ver Ryan (2003).

40 Isso não implica a existência de um vácuo temporal, pois o tempo está na passagem de um momento ao outro, mas a independência ontológica entre ambos os momentos.

41 Pense-se aqui exclusivamente na relação causal, desconsiderando-se as implicações que pode haver se considerarmos o espaço e o tempo como constituídos pelos objetos que os compõem, de modo que não se poderia admitir a existência de um objeto solitário no universo. 
no mundo - e entrar em uma disputa de fantasias próprias, mas observar o seu esquema conceitual.

Hume oferece um argumento:

Voltemos, assim, nosso olhar para dois objetos quaisquer, que chamaremos de causa
e efeito, examinemo-los de todos os lados, a fim de encontrar a impressão que produz
uma ideia de tamanha importância [a causação]. Logo à primeira vista, percebo que
não devo buscar essa impressão em nenhuma das qualidades particulares dos objetos,
pois, qualquer que seja a qualidade que escolho, encontro sempre um objeto que não a
possui e que não obstante se inclui sob a denominação de causa ou de efeito. De fato,
não existe nada, interno ou externo, que não deva ser considerado uma causa ou efeito.
E, entretanto, é claro que não existe nenhuma qualidade que pertença universalmente
a todos os seres, e que lhes dê direito a essa denominação. (TNH 1.3.2.5)

Qualquer objeto, afirma Hume, pode ser considerado causa ou efeito, de modo que todos os objetos podem sê-los. Essa premissa não é problemática dentro da filosofia humiana, ainda que seja possível criticá-la a partir de outras perspectivas ontológicas. Por exemplo, poder-se-ia dizer que Deus não pode ser efeito de nada e que apenas Ele pode ser causa de algo.

Se ser causa (ou efeito) fosse uma qualidade presente nos objetos, ela precisaria ser comum a todos (porque todos podem sê-la). A rejeição dessa premissa implica o compromisso com uma homonímia da causação, isto é, que falamos de causas em diferentes sentidos quando consideramos diferentes casos. Essa é a via do exemplo anterior: os filósofos que defendem que apenas Deus pode ser causa pleiteiam, consequentemente, que, quando afirmamos que o fogo causa a fumaça, falamos em um sentido diferente do que quando dizemos que Deus causa.

Essa é uma querela que não explorarei porque as críticas contemporâneas ao argumento de Hume não a envolvem. Contudo, uma apreciação histórica dele deve dar conta dessa diferença entre Hume e seus interlocutores.

O próximo passo é a afirmação de que nada é comum a todos os objetos. Não é claro o fundamento dessa última premissa. É uma afirmação distinta daquela que é mais óbvia, a de que todos os objetos são diferentes (pois, se não houvesse nenhuma diferença entre dois objetos, eles seriam um e o mesmo). De todo modo, ela pode ser tida como uma alegação empírica a ser tomada como verdadeira até que algum objetor apresente um contraexemplo.

Considerando todos os passos, ser causa não pode ser uma propriedade descoberta pela inspeção de um objeto, ao menos entre as qualidades perceptíveis. Por isso, não é absurdo que se conceba que algo exista sem uma causa para a sua existência, ou seja, não há restrição, diante do que está contido na ideia de cada coisa a partir da sua apreciação isolada, para considerá-la independente de um poder que a tenha originado. 


\section{Conclusão}

O equívoco na análise de Anscombe está em tomar o argumento de Hume como amparado em associações causais particulares, o que não é o caso, uma vez que ele distingue o seu tratamento das associações particulares da análise da máxima causal (TNH 1.3.2.14-15), ou como dependente de uma noção vaga de conceptibilidade que violaria até mesmo a sua crítica às ideias gerais abstratas. Ele é estabelecido a partir da natureza das ideias simples e das limitações que ela impõe ao princípio de conceptibilidade.

A natureza das ideias simples, que as impede de serem criações do espírito, é o fundamento do seu nexo com a realidade. Isso limita o pensamento ao que é possível. As suas combinações em ideias complexas podem ser fantasiosas ou ilusórias, porém isso não é usualmente tido como uma extrapolação do possível.

Ademais, o caráter discreto da percepção e do tempo tornam razoável o isolamento dos conteúdos da experiência e a posição de que eles poderiam existir por si mesmos, sem a necessidade de uma causa para as suas existências. Somente ao considerá-los em seu fluxo, com suas regularidades, é que atribuímos relações de necessidade entre eles, ou seja, não é a partir de um conhecimento prévio à experiência que estabelecemos a máxima causal.

A avaliação correta do argumento de Hume não deve ser feita com foco no exercício imaginativo, no tentar estabelecer um estado de coisas e avaliá-lo a partir dessa imagem. Isso leva ao argumento fraco e pouco convincente que Anscombe nota ao final da sua análise. Ela deve ser realizada à luz dos avanços conceituais anteriores concernentes à natureza da percepção, do tempo e da própria causalidade, que abrem espaço e permitem um raciocínio breve para o tratamento da máxima causal.

\section{Referências}

ANSCOMBE, G. E. M. “Causality and determination”. In: E. Sosa; M Tooley (ed.), 1993. pp. 88-104.

. "Times, Beginnings, and Causes.” In: A. Kenny (ed.), 1986. pp. 86-103.

"“Whatever has a beginning of existence must have a cause': Hume's argument exposed." Analysis 34.5, April 1974, pp. 141-151.

BERKELEY, G. “Obras filosóficas”. Tradução de Jaimir Conte. São Paulo: Ed. UNESP, 2010. [PHK]

BERTO, F., SCHOONEN, T. "Conceivability and possibility: some dilemmas for Humeans". Synthese, Vol. 195, Issue 6, 2018, pp. 2697-2715. DOI: 10.1007/s11229017-1346-7. 
DESCARTES, R. “Oeuvres de Descartes". Ed. Charles Adam \& Paul Tannery. Paris: Libraire Philosophique J. Vrin, 1996. [AT]

GARRETT, D. "Cognition and Commitment in Hume's Philosophy". Oxford: Oxford University Press, 1997.

HUME, D. "Investigações sobre o entendimento humano e sobre os princípios da moral". Tradução de José Oscar de Almeida Marques. São Paulo: Ed. UNESP, 2004. [IEH] . "Tratado da Natureza Humana". Tradução de Deborah Danowski. $2^{\mathrm{a}}$ edição revista e ampliada. São Paulo: Ed. UNESP, 2009. [TNH]

KENNY, A. (ed.). "Rationalism, empiricism, and idealism". Oxford: Oxford University Press, 1986.

KNEALE, W. C. "Probability and Induction". Oxford: Oxford University Press, 1949. LOCKE, J. "Ensaio sobre o entendimento humano". Tradução coordenada por Eduardo Abranches de Soveral. Lisboa: Fundação Calouste Gulbenkian, 1999. ["Ensaio"]

NOONAN, H. "Hume on Knowledge". London: Routledge, 1999.

OSBORNE, G. "Hume's Argument in Treatise 1.3.3.3: An Exposition and Defense". Hume Studies, Vol. 31, Nr. 2, 2005, pp. 225-248.

OWEN, D. "Hume's Reason". Oxford: Oxford University Press, 1999.

RYAN, T. "Hume's Argument for the Temporal Priority of Causes". Hume Studies, Vol. XXVIX, Number 1, April 2003, pp. 29-41.

SOSA, E.; TOOLEY, M. (ed.). "Causation”. Oxford: Oxford University Press, 1993. STROUD, B. "Hume”. London: Routledge, 1977. 